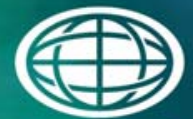

Savannah River

National Laboratory "m

OPERATED BY SAVANNAH RIVER NUCLEAR SOLUTIONS

\title{
Solvent Dispersion and Fow Meter Calculation Results
}

C. A. Nash

F. F. Fondeur

T. B. Peters

June, 2013

SRNL-STI-2013-00275 


\section{DISCLAIMER}

This work was prepared under an agreement with and funded by the U.S. Government. Neither the U.S. Government or its employees, nor any of its contractors, subcontractors or their employees, makes any express or implied:

1. warranty or assumes any legal liability for the accuracy, completeness, or for the use or results of such use of any information, product, or process disclosed; or

2. representation that such use or results of such use would not infringe privately owned rights; or

3. endorsement or recommendation of any specifically identified commercial product, process, or service.

Any views and opinions of authors expressed in this work do not necessarily state or reflect those of the United States Government, or its contractors, or subcontractors.

\section{Printed in the United States of America \\ Prepared for U.S. Department of Energy}




\title{
Solvent Dispersion and Flow Meter Calculation Results
}

\author{
C. A. Nash \\ F. F. Fondeur \\ T. B. Peters
}

June 2013

Prepared for the U.S. Department of Energy under contract number DE-AC09-08SR22470. 


\section{REVIEWS AND APPROVALS}

\section{AUTHORS:}

C. A. Nash, SRNL/Advanced Characterization \& Processing

Date

T. B. Peters, SRNL/Advanced Characterization \& Processing

Date

F. F. Fondeur, SRNL/Separation \& Actinide Science Programs

Date

TECHNICAL REVIEW:

M. R. Poirier, SRNL/Advanced Characterization \& Processing, Reviewed per E7 2.60 Date

\section{APPROVAL:}

F. M. Pennebaker, Manager

Date

SRNL/Advanced Characterization \& Processing

Date

S. L. Marra, Manager

SRNL/Environmental \& Chemical Process Technology Research Programs

E. A. Brass, Manager

Date

SRR/ Flowsheet Integration and Technology 


\section{EXECUTIVE SUMMARY}

Savannah River National Laboratory (SRNL) found that the dispersion numbers for the six combinations of CSSX:Next Generation Solvent (NGS) "blend” and pure NGS versus salt solution, caustic wash, and strip aqueous solutions are all good. The dispersion numbers are indications of processability with centrifugal contactors.

A comparison of solvent physical and thermal properties shows that the Intek ${ }^{\mathrm{TM}}$ solvent flow meter in the plant has a reading biased high versus calibrated flow when NGS is used, versus the standard CSSX solvent. The flow meter, calibrated for CSSX solvent, is predicted to read $2.8 \mathrm{gpm}$ of NGS in a case where the true flow of NGS is 2.16 gpm. 


\section{TABLE OF CONTENTS}

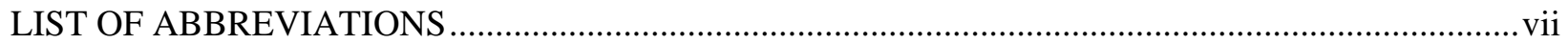

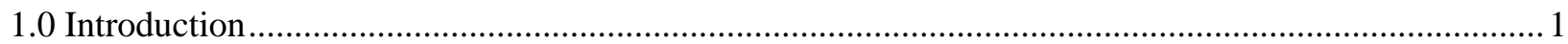

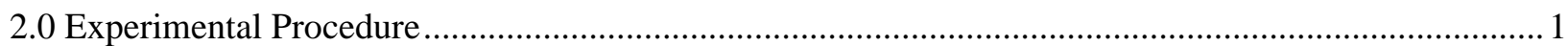

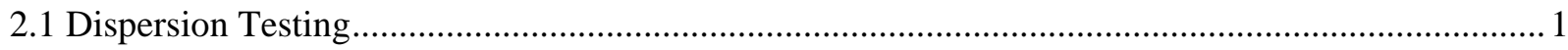

2.2 Physical and Thermal Properties of Solvents ..............................................................................

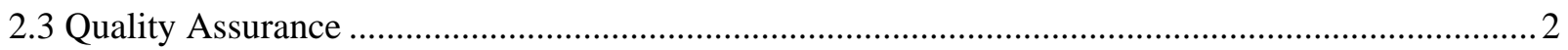

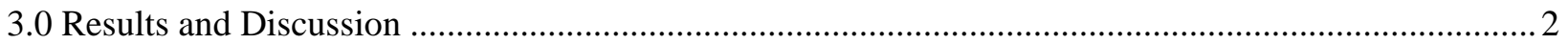

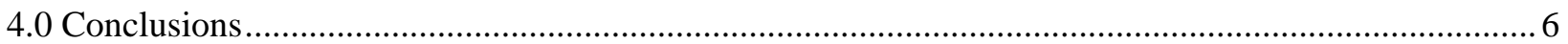

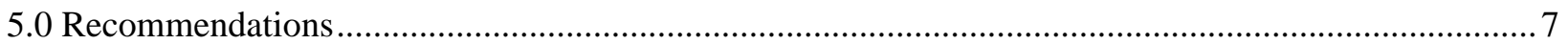

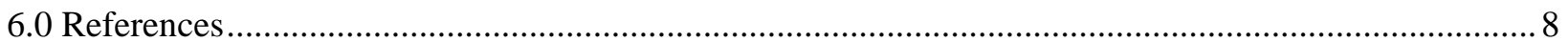




\section{LIST OF ABBREVIATIONS}

$\begin{array}{ll}\text { AD } & \text { Analytical Development } \\ \text { ACP } & \text { Advanced Characterization and Process Technology } \\ \text { Cp } & \text { Heat capacity of solvent } \\ \text { CSSX } & \text { Caustic Side Solvent Extraction } \\ \text { D } & \text { Diameter of flow channel in the Intek }{ }^{\mathrm{TM}} \text { flow meter } \\ \text { DSC } & \text { Differential Scanning Calorimeter } \\ \mathrm{h} & \text { heat transfer coefficient } \\ \mathrm{k} & \text { thermal conductivity } \\ \text { L } & \text { a characteristic flow path length, units of length } \\ \text { MCU } & \text { Modular CSSX Unit } \\ \text { NGS } & \text { Next Generation Solvent } \\ \text { Nu } & \text { Nusselt Number, h*D/k } \\ \text { O:A } & \text { Organic to Aqueous volumetric ratio } \\ \text { Pr } & \text { Prandtl Number, Cp* } \mu / k \\ \text { Re } & \text { Reynolds Number, density* }{ }^{*} \text { D / } \mu \\ \text { RSD } & \text { relative standard deviation } \\ \text { SRNL } & \text { Savannah River National Laboratory } \\ \text { TTR } & \text { task technical request } \\ \text { TTQAP } & \text { task technical and quality assurance plan } \\ \mu & \text { Absolute viscosity of solvent } \\ \text { V } & \text { Velocity of liquid through the Intek }{ }^{\mathrm{TM}} \text { flow meter }\end{array}$




\subsection{Introduction}

This report describes the laboratory and calculated results in support of Modular CSSX Unit (MCU) processing with Next Generation Solvent (NGS). Solvent/aqueous mixture dispersion tests were performed to indicate ability of two phase liquid mixtures to separate. This is an important indicator for the planned use of NGS. Separately, prior and current solvent property measurements were gathered and effects of NGS on the MCU solvent flow meter are evaluated. This work was specified by Technical Task Request (TTR) ${ }^{\mathrm{i}}$ and by Task Technical and Quality Assurance Plan (TTQAP). ${ }^{\text {ii }}$

Details for NGS work are contained in controlled laboratory notebooks.

\subsection{Experimental Procedure}

\subsection{Dispersion Testing}

The dispersion test is a semiquantitative measure of the ability of immiscible organic and aqueous liquids to separate after being mixed. Details of the test and its uses are found in reference 3.ii Implementation of the test is the subject of a work instruction. ${ }^{\text {iv }}$ Testing for this work was conducted at room temperature $\left(23+/-2{ }^{\circ} \mathrm{C}\right)$ using a 50:50 volumetric mixture of current CSSX solvent and NGS "cocktail”, along with batches only having 100\% NGS liquid." Mixing the "cocktail” with CSSX solvent produces a "blend" that will be the first form of NGS solvent to run in the MCU plant. Aqueous phases were salt solution, $0.025 \mathrm{M} \mathrm{NaOH}$ (scrub solution) and 0.01 $\mathrm{M}$ boric acid (strip solution). These are used to support the chemistry of NGS. The solvents and aqueous solutions had not been used in other work. The salt solution had been filtered before use. Solvents and components were stored either in Teflon bottles or clean glassware.

The $100-\mathrm{mL}$ graduated cylinders for the testing were either 0.179 or $0.184 \mathrm{~m}$ in height from the bottom $(0 \mathrm{~mL})$ to the $100-\mathrm{mL}$ mark. The height was noted for the sake of calculating dispersion number for each cylinder:

Dispersion number ${ }^{4}=\left[\left(\text { height, } \mathrm{m} / 9.81 \mathrm{~m} / \mathrm{s}^{2}\right]^{0.5} /\right.$ (break time, seconds)

The break time is the time for the dispersion to coalesce as defined in references 3 and 4 . This is the time for the droplets to break (interface between the liquid phases stops moving) after the graduated cylinder is shaken. If one or two droplets persist at the interface they are ignored and the stopwatch is stopped.

The total volume of liquids in all test cylinders was $100 \mathrm{~mL}$. Table 2-1 shows the specific volumes added. The volumes provide the Organic:Aqueous (O:A) ratios for NGS operation in the plant, these being 1:4 for extraction of salt solution, and O:A 3.75:1 for scrub and strip. When CSSX and NGS cocktail organic liquids were 50:50 by volume, they were premixed before addition to the test cylinders. 
Dispersion testing generally involves adding the required liquids to a clean graduated cylinder with a ground glass top, capping the cylinder, shaking 10 times in about 5 seconds, and measuring the time for the dispersion layer to coalesce when the cylinder is upright and at rest. All test results here were measured on an afternoon then repeated with the same cylinder and material the next morning after the cylinders were allowed to sit undisturbed overnight.

Table 2-1. Liquids used in Dispersion Testing

\begin{tabular}{|c|c|c||}
\hline CSSX Solvent, $\mathbf{m L}$ & NGS, $\mathbf{m L}$ & Aqueous Phase, $\mathbf{~ m L}$ \\
\hline zero & 20 & Salt solution, $80 \mathrm{~mL}$ \\
\hline zero & 79 & $0.025 \mathrm{M} \mathrm{NaOH}, 21 \mathrm{~mL}$ \\
\hline zero & 79 & $0.01 \mathrm{M}$ Boric Acid, $21 \mathrm{~mL}$ \\
\hline $20 \mathrm{~mL}$ CSSX:cocktail blend & Salt solution, $80 \mathrm{~mL}$ \\
\hline $79 \mathrm{~mL}$ CSSX:cocktail blend & $0.025 \mathrm{M} \mathrm{NaOH}, 21 \mathrm{~mL}$ \\
\hline $79 \mathrm{~mL}$ CSSX:cocktail blend & $0.01 \mathrm{M}$ Boric Acid, $21 \mathrm{~mL}$ \\
\hline
\end{tabular}

\subsection{Physical and Thermal Properties of Solvents}

The "Rheotherm" flow meter at MCU uses heat transfer to measure solvent flow rate. The current solvent has different physical and thermal properties from that of NGS, so the effect of changing solvents on flow meter calibration is calculated in this work. Density and viscosity are available from past work as presented and cited in Section 3.2. Thermal conductivity and heat capacity of CSSX solvent and NGS were measured using a DuPont Instruments 910 Differential Scanning Calorimeter (DSC).

\subsection{Quality Assurance}

Requirements for performing reviews of technical reports and the extent of review are established in Manual E7 2.60. SRNL documents the extent and type of review using the SRNL Technical Report Design Checklist contained in WSRC-IM-2002-0001

1, Rev. 2.

\subsection{Results and Discussion}

\subsection{Dispersion Testing Results}

The results of the dispersion measurements are listed in Table 3-1. In all cases in this testing a distinct dispersion band between the upper and lower layers was seen to form about halfway through the test. Progress in coalescence (disappearance) of the band was reasonably steady and easy to track. For the salt solution tests the resulting organic phase was cloudy and the salt solution was slightly cloudy after the dispersion band disappeared. For the other aqueous solution tests the lower aqueous phase was very clear and the organic phase was hazy after each test. All phases in all the tests cleared up overnight. Each cylinder was shaken and timed the next morning to provide the right hand column of data in Table 3-1. 
Table 3-1. Dispersion Number Measurements $\left(23+/-2^{\circ} \mathrm{C}\right)$

\begin{tabular}{|c|c|c|c||}
\hline Organic Phase & Aqueous Phase & $\begin{array}{c}\text { Dispersion } \\
\text { Number } \\
\mathbf{0 4 / 0 8 / 2 0 1 3}\end{array}$ & $\begin{array}{c}\text { Dispersion } \\
\text { Number } \\
\mathbf{0 4 / 0 9 / 2 0 1 3}\end{array}$ \\
\hline NGS & Salt solution & $8.41 \mathrm{E}-04$ & $9.79 \mathrm{E}-04$ \\
\hline NGS & $0.025 \mathrm{M} \mathrm{NaOH}$ & $7.51 \mathrm{E}-04$ & $7.68 \mathrm{E}-04$ \\
\hline NGS & $0.01 \mathrm{M}$ Boric Acid & $9.26 \mathrm{E}-04$ & $8.35 \mathrm{E}-04$ \\
\hline CSSX:NGS Blend & Salt solution & $8.00 \mathrm{E}-04$ & $7.68 \mathrm{E}-04$ \\
\hline CSSX:NGS Blend & 0.025 M NaOH & $8.67 \mathrm{E}-04$ & $6.46 \mathrm{E}-04$ \\
\hline CSSX:NGS Blend & 0.01 M Boric Acid & $6.01 \mathrm{E}-04$ & $6.52 \mathrm{E}-04$ \\
\hline
\end{tabular}

Results here are considered to be in the "good" range per reference 3. Reference 3 states that a dispersion number of 4E-04 is "fair", 8E-04 is "good", and >16E-04 is "excellent" for separation ability. Reference 3 estimates that the standard deviations for measurements are in the range of 10 to 25\%. Past results for CSSX solvent showed slightly higher dispersion numbers, with an average value of $1.15+/-0.21 \mathrm{E}-03$ for the extraction (salt solution) phase. ${ }^{\mathrm{vi}}$

\subsection{Rheotherm Flow Meter Calculations}

The Intek Rheotherm ${ }^{\mathrm{TM}}$ flow meter operates by measuring heat transfer coefficient at the wall of a straight round flow channel within the sensor head. Heat transfer coefficient is a function of liquid velocity and the physical and thermal properties given in Table 3-2. Properties are at 25 $+/-2{ }^{\circ} \mathrm{C}$. Thermal properties were measured at SRNL. Reynolds number Re is (density * flow velocity $\mathrm{V}^{*}$ channel diameter $\mathrm{D} /$ viscosity $\mu$ ). Prandtl number $\operatorname{Pr}$ is (heat capacity Cp $* \mu$ / thermal conductivity k). Fluid velocity only enters the equations as Re. Pr does not depend on geometry but is only a function of fluid properties.

Uncertainties in density are reported to be less than $0.002 \mathrm{~g} / \mathrm{mL}$ for CSSX solvent and less than $0.00028 \mathrm{~g} / \mathrm{mL}$ for NGS, one standard deviation. ${ }^{\mathrm{vivii}}$ One standard deviation for viscosities is 0.1 centipoise (0.001 poise). ${ }^{\text {vii }}$ The thermal properties were determined by comparison with ndodecane and one-sigma uncertainty was estimated to be $5 \%$. 
SRNL-STI-2013-00275

Revision 0

Table 3-2. Physical and Thermal Properties, cgs units

\begin{tabular}{|l|c|c|}
\hline \multicolumn{1}{|c|}{ Property } & CSSX Solvent & NGS \\
\hline Density, g/mL & $0.851^{*}$ & $0.829^{* *}$ \\
\hline $\begin{array}{l}\text { Viscosity, Poise } \\
\left(\text { dyne s)/(cm }{ }^{2}\right)\end{array}$ & $0.036^{*}$ & $0.031^{\chi}$ \\
\hline $\begin{array}{l}\text { Thermal Conductivity, } \\
\left.\text { Cal/(cm }{ }^{\circ} \mathrm{C}\right)\end{array}$ & $3.66 \mathrm{E}-04$ & $4.49 \mathrm{E}-04$ \\
\hline $\begin{array}{l}\text { Heat Capacity, } \\
\left.\text { Cal/(g }{ }^{\circ} \mathrm{C}\right)\end{array}$ & 0.398 & 0.428 \\
\hline $\begin{array}{l}\text { Prandtl Number (Pr), } \\
\text { dimensionless }\end{array}$ & 39.4 & 28.6 \\
\hline $\begin{array}{l}\text { Reynolds Number (Re), } \\
\text { dimensionless, 2.8 gpm }\end{array}$ & 4180 & 4910 \\
\hline
\end{tabular}

*Delmau et al. ${ }^{\text {vii }}$

*** Presented in Peters et al. ${ }^{\text {viii }}$

${ }^{\chi}$ Extrapolation using data from reference vii.

The Dittus-Boelter standard heat transfer correlation was used to model operation of the flow meter. It was found to be suitable down to a Reynolds Number of $4000{ }^{\text {ix }}$ In addition a modified Hausen equation for local Nusselt number was also used. ${ }^{\mathrm{x}}$ This second check was done because the Reynolds number for flow through the Intek ${ }^{\mathrm{TM}}$ meter is in the transition range where heat transfer correlations are not as accurate as they are for laminar and turbulent fluid flow.

The Dittus-Boelter equation is given below:

$$
\mathrm{Nu}=0.021 * \operatorname{Re}^{0.8} * \operatorname{Pr}^{0.4}
$$

Use of this equation found that the leading term 0.021 does not affect the back-calculated velocity indicated by the flow meter as further described below.

The Hausen equation as modified by the authors of reference 10 is:

$$
\mathrm{Nu}=0.0235 *\left(\operatorname{Re}^{0.8}-230\right) *\left(1.8 * \operatorname{Pr}^{0.3}-0.8\right) *\left(1+\left((\mathrm{D} / \mathrm{L})^{2 / 3}\right) / 3\right)
$$

$\mathrm{L}$ is a characteristic tube length leading up to a point where $\mathrm{Nu}$ is calculated. In the current work (D/L) is assumed to be 0.1 (the Intek flow sensor appears to be about 5 inches long with a 0.5 inch flow channel). However, the current calculations found that this term along with the leading proportional term 0.0235 drops out and does not affect the resulting back-conversion of heat transfer coefficient to meter-indicated velocity. 
The general use of a heat transfer coefficient here is to assume that the meter is calibrated for CSSX solvent such that the heat transfer coefficient correlations establish correspondences between liquid velocity through the meter and heat transfer coefficient $h$. By then using the liquid properties of NGS in the correlations one can predict the meter velocity reading (proportional to volumetric flow rate) when the solvent changes from CSSX to NGS.

The effect of each fluid property change on the calibration was calculated by changing the CSSX properties $1 \%$, one at a time. Results in Table 3-3 show that the Hausen equation predicts greater effects on the heat transfer coefficient than does the Dittus-Boelter correlation except for heat capacity. An increase in viscosity reduces heat transfer coefficient as expected. Increasing the other three properties leads to an increase heat transfer coefficient (higher meter reading). The NGS has lower density and viscosity, but higher heat capacity and thermal conductivity than CSSX. The variations in viscosity and the two thermal properties between the solvents favor higher heat transfer with NGS as shown in the sensitivity analysis per Table 3-3.

Table 3-3 \% Change of Heat Transfer Coefficient with 1\% Property Changes

\begin{tabular}{|l|c|c|}
\hline \hline Property & Dittus-Boelter & Modified Hausen \\
\hline & & \\
\hline Viscosity & $-0.40 \%$ & $-0.77 \%$ \\
\hline Density & $0.80 \%$ & $1.13 \%$ \\
\hline Thermal Conductivity & $0.60 \%$ & $0.65 \%$ \\
\hline Heat Capacity & $0.40 \%$ & $0.35 \%$ \\
\hline
\end{tabular}

The differing heat transfer coefficients between the two models are for the most part cancelled out when the heat transfer model is used to back-calculate the indicated velocity, which is proportional to volumetric throughput. The method thus (1) calculates a heat transfer coefficient for CSSX at an assumed flow rate, then (2) inserts that heat transfer coefficient and NGS properties into the same heat transfer equation (using NGS properties now) to back-calculate Reynolds number and thus a new velocity. This represents the NGS velocity that would provide the same heat transfer coefficient as CSSX flowing at the "true" rate. Table 3-4 summarizes the results. 
Table 3-4. Effects of Fluid Properties on Flow Meter Reading

\begin{tabular}{|c|c|c|c|c|c|}
\hline $\begin{array}{l}\text { Heat } \\
\text { Transfer } \\
\text { Model }\end{array}$ & $\begin{array}{l}\text { True } \\
\text { Volumetric } \\
\text { Flow Rate, } \\
\text { gpm }\end{array}$ & $\begin{array}{l}\text { Corresponding } \\
\text { liquid velocity in } \\
\text { the meter, cm/s }\end{array}$ & $\begin{array}{l}\text { Calculated Heat } \\
\text { Transfer } \\
\text { Coefficient, } \\
\mathrm{cal} / \mathrm{s} / \mathrm{cm}^{2} / \mathrm{K}\end{array}$ & $\begin{array}{l}\text { Indicated } \\
\text { Flow Rate, } \\
\text { gpm }\end{array}$ & $\begin{array}{l}\text { Indicated/actual } \\
\text { flow rate, } \\
\text { dimensionless }\end{array}$ \\
\hline \multirow{3}{*}{$\begin{array}{l}\text { Dittus- } \\
\text { Boelter } \\
\text { CSSX }\end{array}$} & 1.6 & 80 & 0.01325 & 1.24 & 0.77 \\
\hline & 2.8 & 140 & 0.02074 & 2.16 & 0.77 \\
\hline & 4.0 & 200 & 0.02758 & 3.09 & 0.77 \\
\hline \multirow{3}{*}{$\begin{array}{l}\text { Dittus- } \\
\text { Boelter } \\
\text { NGS* }\end{array}$} & 1.6 & 80 & 0.01629 & & \\
\hline & 2.8 & 140 & 0.02549 & & \\
\hline & 4.0 & 200 & 0.03391 & & \\
\hline \multirow{3}{*}{$\begin{array}{l}\text { Hausen } \\
\text { CSSX }\end{array}$} & 1.6 & 80 & 0.00911 & 1.28 & 0.80 \\
\hline & 2.8 & 140 & 0.01858 & 2.20 & 0.79 \\
\hline & 4.0 & 200 & 0.02724 & 3.11 & 0.78 \\
\hline \multirow{3}{*}{$\begin{array}{l}\text { Hausen } \\
\text { NGS* }\end{array}$} & 1.6 & 80 & 0.01253 & & \\
\hline & 2.8 & 140 & 0.02433 & & \\
\hline & 4.0 & 200 & 0.03514 & & \\
\hline
\end{tabular}

* These rows display the heat transfer coefficient (h) if NGS is flowing at the true flow rates. In all cases $h$ is higher than if CSSX was flowing at the same rate through the flow meter.

NGS removes heat better than CSSX, so a slower flow rate of NGS provides the same heat transfer as a given flow rate of CSSX. The Dittus-Boelter equation is simple enough that the indicated flow meter deviation is independent of flow rate. In the nominal case only $2.16 \mathrm{gpm}$ of NGS would cause the CSSX-calibrated meter to read $2.8 \mathrm{gpm}$. The Hausen equation, being more complex than Dittus-Boelter, indicates a slight curvature to the change of calibration. In all cases the flow meter will read high compared to the true volumetric flow rate of NGS.

\subsection{Conclusions}

Dispersion numbers for all six combinations of solvent and aqueous phases are all found to exceed 6.0E-04. Reference 3 states that dispersion numbers of 4E-04 is "fair" and 8E-04 is "good" for separation ability. Liquid-liquid centrifugal contactors work best with higher dispersion numbers. The mixed CSSX/NGS and NGS organic liquids are thus found here to pass the dispersion number test for MCU processing.

Heat transfer calculations show that the Intek Rheotherm ${ }^{\mathrm{TM}}$ flow meter will read about $22 \%$ high when CSSX is replaced by NGS. Two separate heat transfer correlations provide close to the same result, and both indicate that NGS is significantly better than CSSX for removing heat from the small heated sensor that the flow meter operates on. Under the current calibration the meter will read $2.8 \mathrm{gpm}$ if $2.8 \mathrm{gpm}$ of CSSX is flowing, or will read $2.8 \mathrm{gpm}$ if $2.16 \mathrm{gpm}$ of NGS is 
flowing. Blend solvent has the same modifier molarity in Isopar ${ }^{\mathrm{TM}} \mathrm{L}$ as does NGS, so its thermal properties should be the same as NGS.

\subsection{Recommendations}

The heat transfer calculation for the Intek flow meter provided a percentage calibration offset to reduce the indicated reading vs. the CSSX calibration when NGS is flowing. It is recommended to apply this, however, it is recommended to verify calibration. Intek recommends calibration verification at least annually. The Intek unit calibration can be adjusted within the meter electronics per the Intek Operating Manual, or per an adjustment of the flow signal processing outside of the meter. 
SRNL-STI-2013-00275

Revision 0

\subsection{References}

${ }^{i}$ E. T. Ketusky, TTR “Technical Task Request - FY2013 SRNL Testing and Support for TF Aspects of NGS”, HLW-TTR-2012-010, Rev. 2, March 14, 2013.

ii T. B. Peters, S. D. Fink, and C. A. Nash, "Task Technical and Quality Assurance Plan for Cesium Mass Transfer Test with Next Generation Solvent (NGS) and Miscellaneous White Papers”, SRNL-RP-201200842, Rev. 1, March, 2013.

iii R. A. Leonard, "Solvent Characterization using the Dispersion Number”, Sep. Sci and Tech., 30 (7-9), pg. 1103-1122, 1995.

iv T. B. Peters, "Dispersion Number Testing for Mixed Aqueous-Organic Mixtures", Work Instruction IWPT-012, rev. 1, October 4, 2011.

v E. T. Ketusky, "Recommended Quantities of Solvent Constituents for Next Generation Solvent (NGS)", SRR-SPT-2012-00039, November 7, 2012.

vi B. A. Moyer, "Caustic-Side Solvent Extraction Chemical and Physical Properties Progress in FY2000 and FY2001”, ORNL/TM-2001/285, February, 2002.

${ }^{v i i}$ L. H. Delmau et al., "Caustic-Side Solvent Extraction: Chemical and Physical Properties of the Optimized Solvent”, ORNL/TM-2002/190, October, 2002.

viii T. B. Peters, A. L. Washington II, and S. D. Fink, "Results of Analyses of the Next Generation Solvent for Parsons”, SRNL-STI-2012-00065, rev. 0, February 2012.

${ }^{\text {ix }}$ D. M. McEligot, L. W. Ormand, and H. C. Perkins, "Internal Low Reynolds-Number Turbulent and Transitional Gas Flow with Heat Transfer”, Journal of Heat Transfer, vol 88, pp. 239-245 (1966).

${ }^{\mathrm{x}}$ W. Roetzel, "Measurement of Heat Transfer Coefficients in Tubes by Temperature Oscillation Analysis", Chemical Engineering Technology, vol. 12, pp. 379-387 (1989). 


\section{Distribution:}

S. L. Marra, 773-A

T. B. Brown, 773-A

D. R. Click, 999-W

S. D. Fink, 773-A

C. C. Herman, 773-A

E. N. Hoffman, 999-W

F. M. Pennebaker, 773-42A

W. R. Wilmarth, 773-A

Records Administration (EDWS)

E. A. Brass, 249-8H

C. K. Chiu, 704-27S

S. E. Campbell, 241-197H

E. J. Freed, 704-S

A. G. Garrison, 248-9H

B. A. Gifford, 704-56H

E. T. Ketusky, 249-8H

K. L. Lang, 707-7E

T. A. Le, 766-H

D. J. Martin, 241-152H

A. R. Shafer, 704-27S

R. H. Spires, 248-8H

R. M. Wolfenden, 704-56 H

P. R. Jackson, DOE-SR, 703-46A

K. H. Subramanian, 241-156H

W. A. Drown, 773-41A 